\title{
Communication strategies to address geohydrological risks: the POLARIS web initiative in Italy
}

\author{
Paola Salvati $^{1}$, Umberto Pernice ${ }^{2}$, Cinzia Bianchi ${ }^{1}$, Ivan Marchesini ${ }^{1}$, Federica Fiorucci ${ }^{1}$, and Fausto Guzzetti ${ }^{1}$ \\ ${ }^{1}$ Consiglio Nazionale delle Ricerche, Istituto di Ricerca per la Protezione Idrogeologica, via Madonna Alta 126, \\ 06128 Perugia, Italy \\ ${ }^{2}$ Innovation Consultant, Viale Michelangelo 2315, 90135 Palermo, Italy
}

Correspondence to: Paola Salvati (paola.salvati@irpi.cnr.it)

Received: 30 December 2015 - Published in Nat. Hazards Earth Syst. Sci. Discuss.: 19 January 2016

Revised: 27 May 2016 - Accepted: 2 June 2016 - Published: 28 June 2016

\begin{abstract}
Floods and landslides are common phenomena that cause serious damage and pose a severe threat to the population of Italy. The social and economic impact of floods and landslides in Italy is severe, and strategies to target the mitigation of the effects of these phenomena are needed. In the last few years, the scientific community has started to use web technology to communicate information on geohydrological hazards and the associated risks. However, the communication is often targeted at technical experts. In the attempt to communicate relevant information on geohydrological hazards with potential human consequences to a broader audience, we designed the POpoLazione A RISchio (POLARIS) website. POLARIS publishes accurate information on geohydrological risk to the population of Italy, including periodic reports on landslide and flood risk, analyses of specific damaging events and blog posts on landslide and flood events. By monitoring the access to POLARIS in the 21-month period between January 2014 and October 2015, we found that access increased during particularly damaging geohydrological events and immediately after the website was advertised by press releases. POLARIS demonstrates that the scientific community can implement suitable communication strategies that address different societal audiences, exploiting the role of mass media and social media. The strategies can help multiple audiences understand how risks can be reduced through appropriate measures and behaviours, contributing to increasing the resilience of the population to geohydrological risk.
\end{abstract}

\section{Introduction}

Geohydrological hazards, including floods and landslides, are common geohydrological phenomena that cause serious damage and pose severe threats to the population worldwide. Currently, river flooding annually affects 21 million people worldwide, and the estimate is expected to reach 54 million people by 2030 (http://www.wri.org). For landslides, Petley (2012) showed that human losses were considerably higher than had been previously considered. Global costs of geohydrological disasters have increased in recent decades and it is expected that in future decades the number of people at risk and the occurrence of extreme events will both grow (https://www.ipcc.ch). Integrated risk management involving public authorities, research scientists, companies and citizens is required to address the interconnectivity between physical infrastructures, economic systems and the role of human factors (Jonkman and Dawson, 2012). The approach should encompass, in a coordinated way, all the necessary activities to maintain a level of security with regard the risk posed by natural hazards (http://www.climchalp.org/), including exchange of information and experience between public bodies, business bodies and citizens.

The availability of detailed and organised information on the geographical and temporal distribution of geohydrological events and their consequences, communicated throughout different media channels, is important for implementing national communication strategies and preparedness programmes. In Italy, detailed information on landslides and floods is available, and catalogues of landslide and flood events with fatalities have been organised and constantly 
updated (Guzzetti et al., 1994, 2005; Guzzetti and Tonelli, 2004; Salvati et al., 2010, 2012, 2013). For this country, in recent decades, much effort has been exerted to analyse landslide and flood hazards and the associated risk at various geographical scales, from the site-specific (local) to the synoptic (national) scale. Despite these efforts, most of these studies remain unknown to the public, who ignore the possible damaging effects that landslides and floods can produce (Salvati et al., 2014). Despite the large number and wide geographical distribution of landslide and flood events, the Italian population receives minimal information and has minimal knowledge on the types, characteristics, frequency and severity of the harmful events that have occurred in the area where they live or work. The lack of knowledge is amplified by people's weak motivation to be informed and as a consequence they demonstrate a weak understanding and perception of geohydrological risk (Salvati et al., 2014).

Although, in the last few years, the Italian scientific community has begun to communicate information on geohydrological hazards and the associated risks through communication initiatives and thematic websites (http://avi.gndci.cnr.it//http://sici.irpi.cnr.it/; http: //www.isprambiente.gov.it/it/progetti/suolo-e-territorio-1/ iffi-inventario-dei-fenomeni-franosi-in-italia; http: //www.pcn.minambiente.it/GN/); these often suffer from the lack of effective communication strategies capable of addressing various targets with suitable media. Consequently, the initiatives remain addressed mainly to experts for specific technical purposes, with content and web interfaces that are barely appreciated by a wider audience and rarely synchronised with social media networks.

Various problems emerged when designing the communication strategy. First, public interest in the issue is important. As Keys (1999) noted, "It has been apparent for some time that creating community awareness of floods and storms is not easy, (...) Most of the time, people are not particularly interested in them" (cited by O'Neil, 2004). The core of the problem is to capture public attention and, with long-term actions, familiarise people to the topic. Knowledge-oriented risk communication campaigns on the causes and dynamics of geohydrological hazards and their possible consequences to human life, conducted with appropriate frequency, can effectively increase public awareness of geohydrological hazards. Second, it is important to find the appropriate mediators to reach the largest number of people. Media represent key mediators of communication between different audiences, i.e. the public, scientists, policy-makers and the operational management (Beck, 1992). They act as social glue with respect to the perception and interpretation of natural hazards in heterogeneous societies (Miles and Morse, 2007).

The mission of the POpoLazione A RISchio (POLARIS) website http://polaris.irpi.cnr.it is to provide correct and reliable information mainly to the media, which will help to further communicate the information to other audiences. In addition, the role of social media should be carefully con- sidered to engage audiences that are typically weakly interested in information on geohydrological risk. Thus, efforts were made to improve the link between the POLARIS website and the Facebook page (https://www.facebook.com/ CNR.IRPI) of the Istituto di Ricerca per la Protezione Idrogeologica (IRPI, http://www.irpi.cnr.it), of the Italian Consiglio Nazionale delle Ricerche (CNR, http://www.cnr.it), by conveying immediate and concise information on natural disasters using pictures and videos, interspersed with invitations to visit the POLARIS website for detailed information.

Following an overview of the literature on natural hazard risk communication in this paper, we describe the website information architecture and analyse the users' navigation data during the 21-month period since the website was published. Then, we explain possible relations between the maximum access and the context in which it occurred. Finally, we discuss possible future improvement of the site and conclude by summarising our findings.

\section{Background in risk communication and perception}

Extensive discussions have occurred in the past about the most appropriate ways to manage the potential consequences of natural hazards (Scolobig et al., 2015), and governments began to institutionalise disaster risk management processes and practices (McEntire, 2006). More recently, an integrated approach to risk management processes is emerging, encompassing activities needed to preserve a level of safety with regard the risk posed by natural hazards (http://www. climchalp.org/) in a coordinated way. Initially associated with environmental management, public health and emergency management matter, risk communication aims at informing people about a potential hazard and the associated harms (Steelman and McCaffrey, 2012). In the last decade, the relevance of communication has been increasing in response to the changes affecting risk governance (Höppner et al., 2010). Accordingly, communication must serve multiple purposes: spanning all phases of risk management (Renn, 2005), enabling more effective decisions, knowledge-based actions (Höppner et al., 2010) and addressing the exchange of knowledge and attitudes between all the involved actors (i.e. public bodies, private sectors, third sector, citizens). In this context, public participation is crucial and defined as co-decision in planning processes designed by others, where the central elements of the participation concept are influence, interaction and information exchange (Bostenaru Dan, 2004). Starting in the 1990s, extensive public consultation and participation in risk management have focused on reestablishing public trust (Rowe et al., 2004). The appropriate transfer of knowledge between experts and the broader public can be facilitated by effective communication strategies and programmes at national or local level to align the views of the public with those of the experts (Frewer, 2004). More recently, the increased attention of public institutions 
for stimulating the participation of citizens in the definition and delivery of public services is leading to the adoption of a citizen-centred risk management approach which takes into account social concerns and citizens' perceptions of risks.

Risk perception is also important for determining the attitude towards risks and, when information campaigns and risk communication strategies are designed, the public perception should be known (Plapp and Werner, 2006). Risk perception is a subjective assessment of the hazard occurrence probability and people's feelings towards the consequences (Nenciu Posner and Armas, 2014). A gap between the public perception of their own responsibility and that of the authorities in terms of risk reduction was found by FernándezBilbao and Twigger-Ross (2009) who, working in England and Germany, found that the public did not perceive reducing flood risk as their responsibility. Plattner et al. (2006) highlighted a systematic discrepancy between the individual subjective risk evaluation (perceived) and formal risk evaluation procedures. Similarly in Italy, two national surveys conducted to measure the public perception of landslide and flood risk confirmed that in most of the Italian regions the observed perception of the threat did not match the long-term risk posed by landslides and floods to the population (Salvati et al., 2014).

If it is globally accepted that risk perception has strong implications for the success of risk communication, it is also expected that effective risk communication shapes risk perception (Höppner et al., 2010). There are many studies trying to establish which formats of communication may be most effective (e.g. Faulkner and Ball, 2007; Fernandez-Bilbao and Twigger-Ross, 2009; Kashefi and Walker, 2009; Bier, 2001). Three phases of risk communication were identified by Leiss (1996) in the USA, including one-way communication, persuasive communication and two-way communication. As Höppner et al. (2010) reported, the first is primarily used to convey probabilistic information, educate the public at risk and gain consent over risk management practices, whereas the second is thought to change people's risk-related behaviours. In the latter phase, all actors should engage with, and learn from each other (Renn, 2005). Risk communication is a complex activity moving from the one-way distribution of information towards a two-way exchange of knowledge and more participatory approach (Höppner et al., 2010). Despite this, the latter communication approach seems to be more effective. In the review work conducted by Höppner et al. (2010) of the communication practices xperienced by governmental authorities, national and local agencies, the majority resulted in one-way efforts and focused on raising or improving risk awareness and knowledge of flood hazards.

\section{Nomenclature}

In this work, we adopt the terminology and definitions used in Google Analytics. We use the term session to indicate the

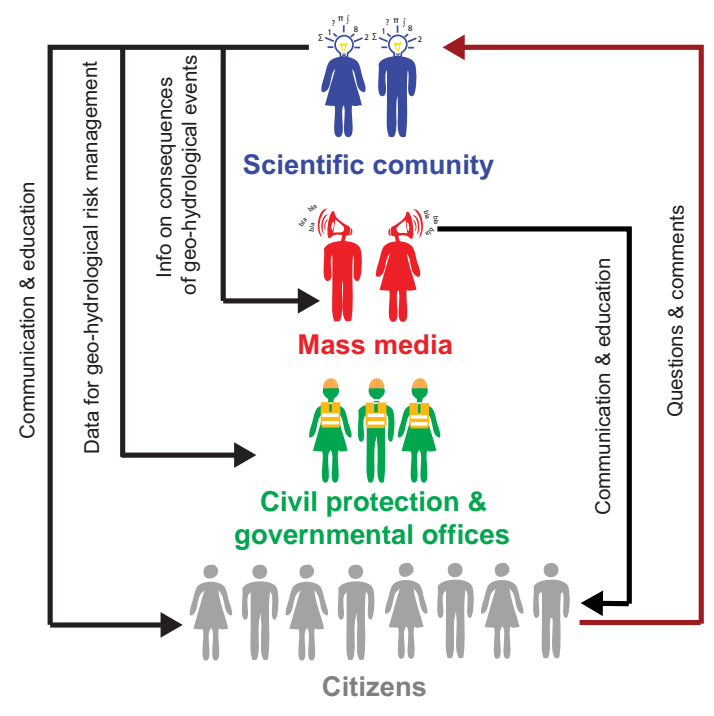

Figure 1. The POLARIS communication flow.

period of time a user is actively engaged with the POLARIS website. All usage data (screen views, events, e-commerce) are associated to a session. Users are people who have had at least one session in the selected date range, including new and returning users. Page views are the total number of pages viewed, including repeated views of the same page. The source is the place users were before viewing POLARIS website content, including a search engine or another website. Referral traffic is Google's method of reporting visitors that arrived at a specific site from sources outside their search engine.

\section{POLARIS website}

The effectiveness of the POLARIS communication strategy relies on the main assumption that the scientific community can play a key role in increasing awareness (Bier, 2001) of individuals and groups on geohydrological hazards and on the type and extent of the risk posed by geohydrological hazards to the population. This role should be attained by working in two directions: (i) providing mass media (e.g. journalists) with correct and reliable information which they can communicate (spread) further to the broader civil society and (ii) adopting less technical and more widely comprehensible language to better engage citizens. Figure 1 shows the communication flow adopted in POLARIS, in which the scientists use different communication approaches to mass media, civil protection and local/regional authorities and to citizens. In this framework, the media captures information from scientists and uses it for communication purposes.

The scientific and technical content of POLARIS is based on a communication strategy that avoids scientific and technical terminology in favour of more widely understandable language. For this purpose, consultants experienced in web 


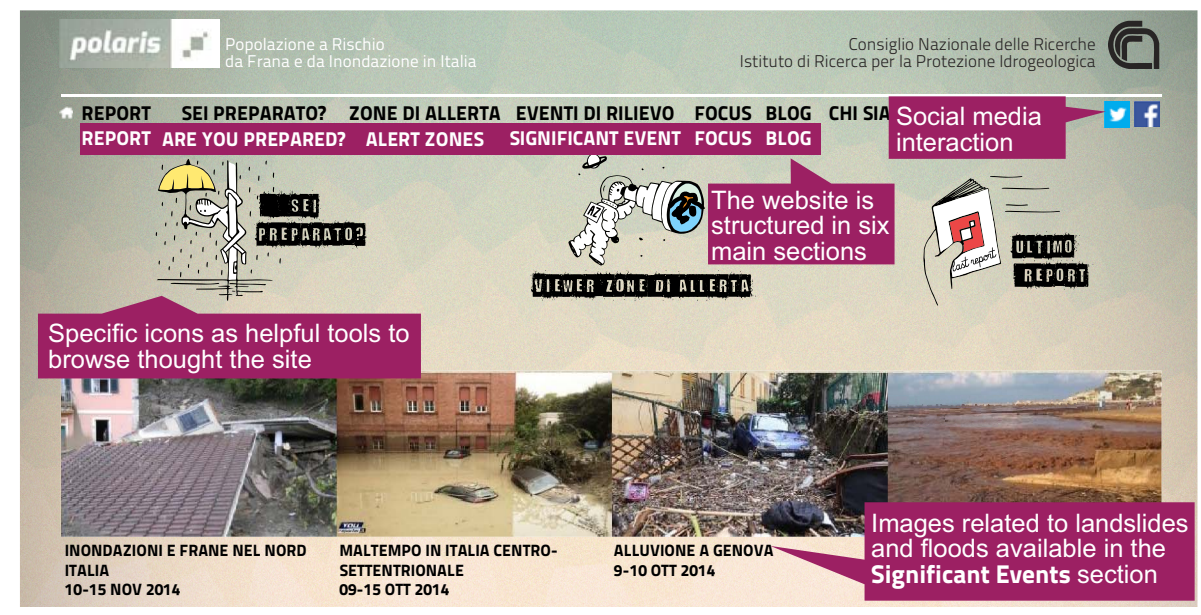

Figure 2. The POLARIS Home Page (http://polaris.irpi.cnr.it). Violet boxes show English translations of the original Italian text.
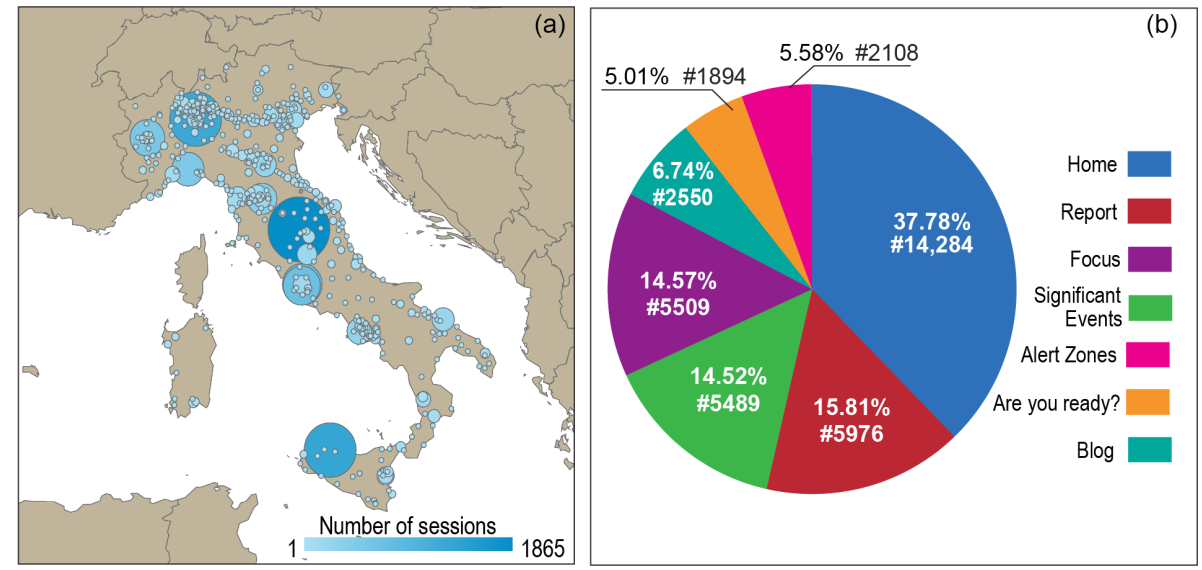

Figure 3. General statistics from Google Analytics for the 638-day period from 16 January 2014 to 15 October 2015. (a) Map showing the geographical distribution of the sessions in Italy. (b) Pie chart shows number of page views for different sections of the website.

communication strategies on natural hazards, infographics and user experience design were involved in the initiative. The consultants' contribution consisted of arranging the messages using intuitive and engaging web interfaces to display data, graphs, tables, video and in carefully considering usability and accessibility of the website to diversified audiences.

POLARIS is based on well-defined information architecture encompassing six main sections: (i) Reports, (ii) Are you prepared?, (iii) Events, (iv) Alert Zones, (v) Focus and (vi) Blog. The sections provide different and complementary information, including (i) periodical reports with analyses of landslide and flood risk to the population of Italy, (ii) suggestions on suitable behaviours to adopt before, during and after potentially damaging events, (iii) data and synthetic analyses of specific geohydrological events with human consequences, (iv) visual information on the morphology, geology and historical damaging events of the Alert Zones used by the Italian Civil Protection system for issuing warnings on meteorological, hydrological and geomorphological hazards, (v) detailed analyses of relevant topics or specific events with severe consequences and (vi) blog-posts on landslide and flood events aimed at encouraging citizens' engagement. Figure 2 shows the POLARIS home page, with specifically designed images and graphics to help browse the website.

\subsection{Structure of the POLARIS website}

The Reports section illustrates periodic reports on landslide and flood risk to the population of Italy. Reports are published every six months. The last report is available in two formats: (i) an online version and (ii) a standard Adobe ${ }^{\circledR}$ PDF (Portable Document Format) file that can be downloaded. The online report is directly integrated with the CNR IRPI Spatial Data Infrastructure (SDI; Salvati et al., 2013), where the database is located, and it has access to data kept updated regularly. Each report contains the list of landslides and floods that occurred in a period (six months or a year), with 
information on the date, location, dead and missing persons, injured people, maps, statistics and an analysis of the landslide and flood events with direct consequences to the population. Statistics are available for different periods of one, five and fifty years, enabling comparative analyses of the geographical and temporal variations of geohydrological risk in Italy.

The Events section publishes information on specific meteorological events in Italy, using text, maps, videos, photographs and drawings. In this section, specific icons were designed to define the type of the geohydrological events. A short text containing information on the sites affected, the damage and the fatalities or casualties is given, with a map showing the location of landslide and flood that affected the population. The Focus section publishes information on specific topics, provides analysis for each Italian region and offers descriptions of single historical or recent catastrophic geohydrological events. The Events and Focus sections jointly inform the population on the extent and severity of geohydrological risk in Italy. They also represent an important source of information and data for the mass media.

The Alert Zones section provides information for 134 Alert Zones defined by the Italian National Civil Protection system to forecast geohydrological hazards, including landslides and floods. The section provides the possibility to query a number of information items and a sidebar offers access to different thematic layers and maps for each Alert Zone.

The Are you prepared? section offers information on suitable (and unsuitable) behaviours to adopt before, during and after a damaging geohydrological event. The suggested elementary behavioural rules may save people's lives.

Finally, the Blog section encourages bottom-up participation by users, who can post comments on geohydrologic hazards and risks.

In the home page, particular focus is reserved to a section called "It Happened Today" (Italian: Accadde oggi), which is a daily register of events in which, for each day of the year, POLARIS publishes a short description of relevant events that adversely impacted the population on that specific day. This section is directly linked to the CNR IRPI SDI, which daily automatically relates the event to the exact day.

\section{Data}

We use Google Analytics to monitor the traffic and performance of the POLARIS website, focusing our analysis on (i) channels used, (ii) number of sessions, (iii) number of users, (iv) users viewing single pages or the entire website and (v) the geographical distribution of the users. We further monitored POLARIS' Facebook page using "Insight" instruments, particularly the number of "likes" given by users or the number of users who viewed the posts. We also per- formed an analysis of the type of posts (containing video, link, images or text alone) that were most popular and the most interested users and their origin.

\section{Analysis and results}

In this section, we describe the performed analysis to identify possible trends of interest to the POLARIS content, and the dependence between peak access values to the website and possible causes that increased the public interest in the website. We also performed similar analysis for the CNR IRPI Facebook page, which is the institute's most active social network.

\subsection{POLARIS website}

The analysis of the data series available from Google Analytics for the period of the website publication, from 16 January 2014 to 15 October 2015, allowed us to prepare general statistics summarised in Table 1, where we listed the data separately for sessions, users, page views and referrals from social networks. We studied the geographical distribution of the users and the number of page views for each section of the website. Results are shown in Fig. 3.

Since POLARIS is published in Italian, it is not surprising that the sessions mainly originate from Italy (91\%). Figure $3 \mathrm{a}$ shows the geographical distribution of the sessions in Italy. The limited percentage of sessions originating from other nations is concentrated in the USA, China, Japan and Germany. Darker and larger dots on the map show the increasing number of sessions, with few areas where sessions are highly concentrated. The largest number of sessions originate from Umbria, where the main office of CNR IRPI is located. Other areas from where POLARIS was accessed frequently include Rome, where the majority of the government offices are located, Milan (Lombardy), Turin (Piedmont), Genoa (Liguria) and Palermo (Sicily). These cities host institutes and researchers who are interested in geohydrological issues. Collectively, they also host 6 million people, $10 \%$ of the entire population of Italy.

The pie chart in Fig. 3 shows the number of page views for the different sections of the website. Not surprisingly, the home page is the most viewed page, containing, in addition to the navigation menu, the It Happened Today (Accadde Oggi) section, which is read by many people, most probably because the content changes daily. The second most-viewed section is the Report section, which publishes periodic reports on the risks posed to the Italian population by landslides and floods. This section is updated every six months and allows to download the reports as PDF files. The Focus and Event sections have similar access percentages. Their content is simple to read and straightforward to understand thanks to explicative figures and maps. The content differs in the subjects; on the Focus page, we discuss in-depth issues related to 


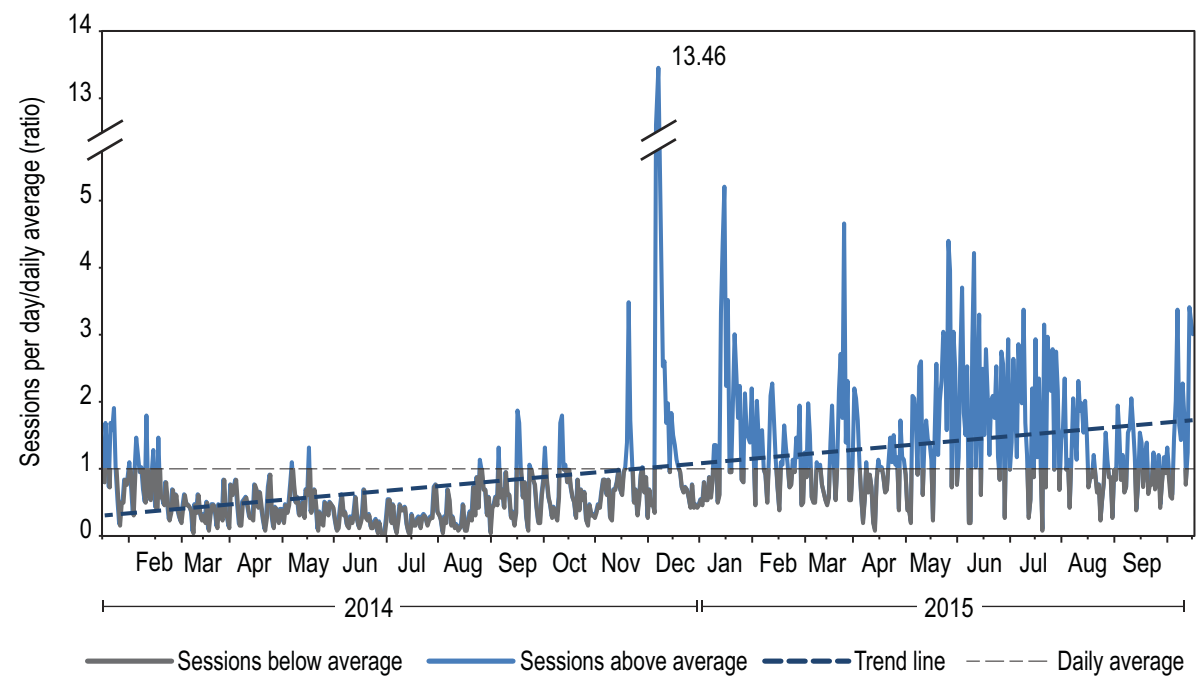

Figure 4. Daily average access number to the POLARIS website in the 638-day period from 16 January 2014 to 15 October 2015.
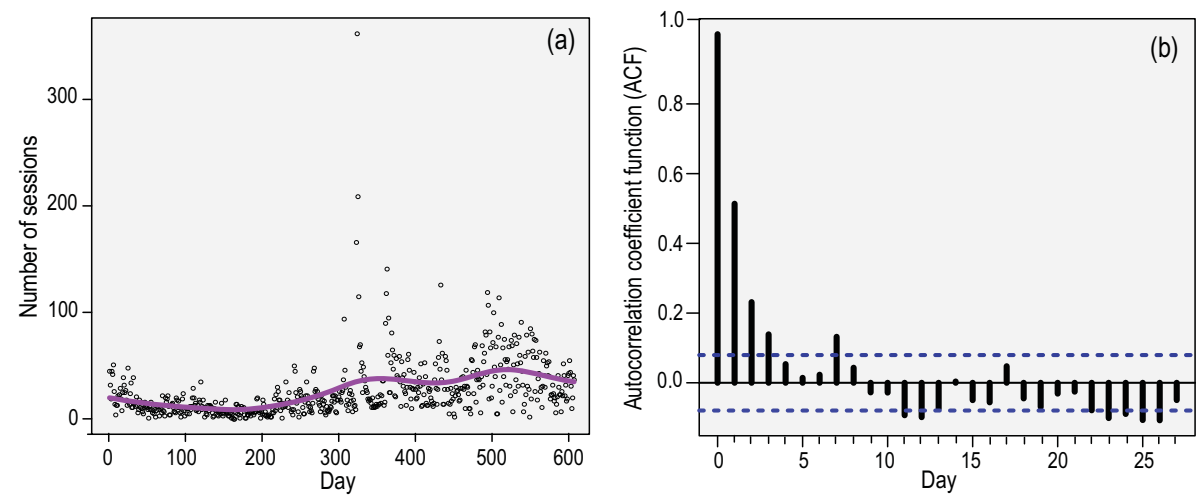

Figure 5. (a) Plot shows the original data (points) and the line (violet line) describing its trend. (b) Chart shows autocorrelation coefficient function (ACF) calculated using the time series of the number of sessions of the POLARIS website.

geohydrological hazards and risks, whereas the Events section is dedicated to the description of specific events that caused damages to the Italian population. The Alerts Zones and Are You Prepared? sections were not accessed as much as expected, although they both contain relevant information and suggestions to help develop suitable behaviour towards disaster resilience.

Monitoring the number of sessions during the 21 months since the website's publication, it was possible to study their temporal distribution. For the purpose, we normalized the number of sessions per day to the daily average number of sessions in the 21-month period (long-term average, 26.9). Results are shown in Fig. 4, where the ratio in the $x$ axis represents the daily access number divided by the average access number in the observation period. The grey parts of the line show periods below the long-term average, and the blue parts show periods above the long-term average. Inspection of Fig. 4 reveals that there was an increase in the number of sessions (blue dashed line in Fig. 4) and significant variations in the daily distribution are also evident. We note that in 350 days of 2014, 42 days (12\%) were above average and 308 days (88\%) were below average. In the 288 days of 2015 (until 15 October 2015), the trend changed, with 182 days $(63.2 \%)$ above the long-term average (Table 1$)$.

To investigate the possibility of a repeating pattern or periodic signal in the record, the time series with the number of sessions were analysed using the autocorrelation function (ACF). The ACF measures the degree of correlation between a signal and the signal itself shifted by a given lag and is defined as follows:

$\mathrm{ACF}=\frac{1}{n \sigma^{2}} \sum_{1}^{n-k}\left(X_{i}-\bar{x}\right)\left(X_{i+k}-\bar{x}\right)$,

where $k$ is the lag (a day in this case), $n$ is the length of the time series (607 days), $\sigma$ is the standard deviation of the values (i.e. the standard deviation of the number of sessions), $\bar{x}$ is the average of the values (i.e. the average of the number of sessions) and $X_{i}$ is a given value of the time series 
Table 1. POLARIS website general statistic for sessions, users, page views and referrals from social networks, calculated using Google Analytics data.

\begin{tabular}{|c|c|c|}
\hline & Statistics & Number \\
\hline \multirow{5}{*}{ Sessions } & Total & 17159 \\
\hline & Daily average & 26.9 \\
\hline & Average duration & $00: 02: 38$ \\
\hline & Days above average (2014) & $42(12 \%)$ \\
\hline & Days above average (2015) & $182(63.2 \%)$ \\
\hline \multirow{4}{*}{ Users } & Total & 11529 \\
\hline & Daily average & 23.3 \\
\hline & Days above average (2014) & $37(10.6 \%)$ \\
\hline & Days above average (2015) & $180(62.5 \%)$ \\
\hline \multirow{12}{*}{ Page views } & Total & 44032 \\
\hline & Daily average & 69 \\
\hline & Average per session & 2.6 \\
\hline & Days above average (2014) & $68(19.4 \%)$ \\
\hline & Days above average (2015) & $165(57.3 \%)$ \\
\hline & Home page & 14284 \\
\hline & Report section & 5976 \\
\hline & Focus section & 5509 \\
\hline & Significant Event section & 5489 \\
\hline & Blog section & 2550 \\
\hline & Alert Zones section & 2108 \\
\hline & Are You Prepared? section & 1894 \\
\hline \multirow{4}{*}{ Referrals } & Total from social network & 2394 \\
\hline & Facebook & $1917(80 \%)$ \\
\hline & Twitter & $430(18 \%)$ \\
\hline & Other social networks & $47(2 \%)$ \\
\hline
\end{tabular}

(the value of the number of sessions of the day $i$ ). Due to the evident increasing trend (non-stationary) in the average number of sessions during the observation period (dashed line in Fig. 4), data have been detrended. The trend has been defined fitting a curved line (Fig. 5a) obtained applying a smoother kernel based on a normal weight function in a bandwidth of 100 days. Figure $5 b$ shows the coefficients (ACF) calculated per different lag times. The autocorrelation value varies between 1 and -1 , and the area between the blue dashed lines represents non-significant autocorrelation values. The analysis revealed that the value of ACF decreases when the lag $k$ (days) increases, and that a marginally significant value of autocorrelation can be observed only for a lag of seven days (a week). However, because the correlation value is not significant at 14 or 21 days, we conclude that the time series of the number of sessions of the POLARIS website does not show evidence of a periodic pattern. The same analysis was performed, detrending the data fitting a linear interpolation (dashed line in Fig. 4). Again, the analysis did not reveal a periodic trend.

To gain a better understanding of the temporal distribution of the user access and to identify peak values, we used the daily number of users and page views obtained from Google
Analytics. We then related the peak values to several factors, including (i) the occurrence of harmful geohydrological events, (ii) the daily early warnings from the Italian $\mathrm{Na}-$ tional Department of Civil Protection, (iii) the publication of new content in the web site, (iv) the publication of press releases that used our data and (v) the promotion of the website through media.

Figure 6 shows the daily user statistics (Fig. 6a), and a comparison between users and number of page views (Fig. 6b) for the 21-month period of website publication, with icons located to identify possible relations. We note how the relation between the peak values and the occurrences of the harmful events until December 2014 became increasingly less relevant since the early months of 2015. In particular, during the period ranging from 15 January to 31 December 2014 , the majority of peaks were registered in the interim of the harmful event occurrences, i.e. on 16-22 January (25 users, 51 sessions, 425 page views), when the two Italian regions of Liguria and Emilia Romagna were hit by heavy rain, which caused two fatalities, and a railway interruption to France was caused by a landslide. Similarly, on 6-15 October, an event hit Liguria and other regions in the north of Italy, causing four deaths and generating a peak of 44 users, 48 sessions and 115 page views. Other correspondences were identified with the icons used to indicate the events, the same as those we used to indicate the type of event (landslide, flood and geohydrological events) on the website. Other peak values were related to the publication of new content. A peak occurred on 15 September 2014 due to a post dedicated to a relevant paper published by the CNR IRPI researchers (38 users, 50 sessions and 110 page views); it also occurred on 19 November, due to the publication of the Are you prepared? section, explaining how to behave during geohydrological events (80 users, 94 sessions and 192 page views). The maximum value was registered when the website was promoted through television by a meteorologist during an evening national broadcasting programme (338 users, 362 sessions and 951 page views).

Another important value corresponds to the press release launch on 13 January 2015, which disseminated the annual report on the geohydrological risk to the population; this was prepared for 2014 and available in the Report section (119 users, 141 sessions, 436 page views). After these announcements, the site began to be consulted by journalists, technicians of different government offices and agencies working on land management. This finding is confirmed by the publication of POLARIS's maps and statistics in national newspapers and in online media corresponding to major event occurrences that captured the interest of the public and to the citation of the website URL in reports published by national or regional institutions. The finding means that POLARIS offers quick and easy access to essential information on geohydrological hazards and risks.

During 2015, the relation with the occurrence of the events decreased; however, the relation with the publications of 

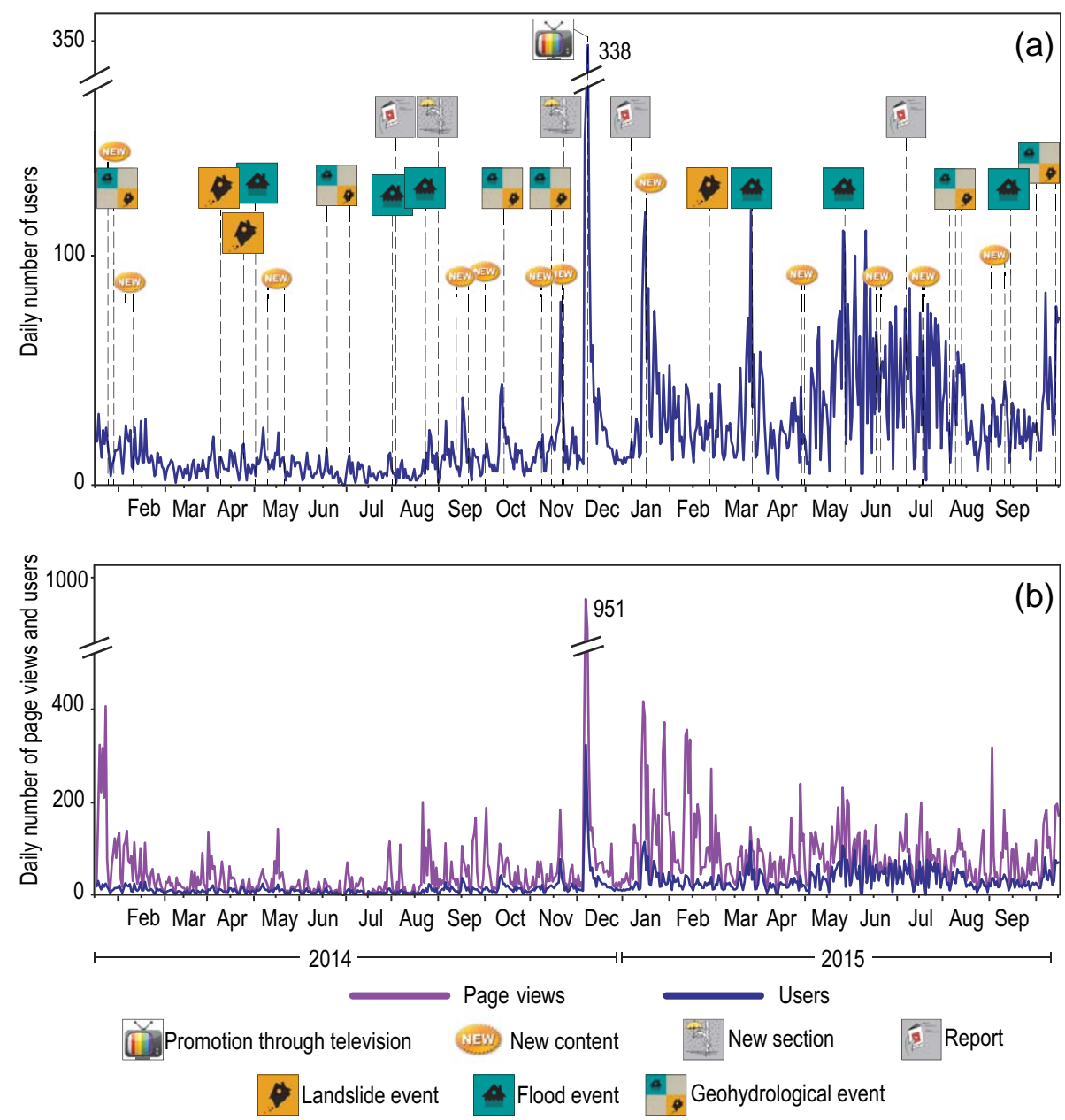

Figure 6. (a) Daily number of users of the POLARIS web site in the 638-day period from 16 January 2014 to 15 October 2015 . (b) Daily number of page views (violet line) and users (blue line) in the same period.

new content became more significant. Analysing the sources where the POLARIS traffic originates daily, we found that other peaks were the consequences of the daily activity of users from government offices or agencies. In Fig. 6b, we plotted the users and the page views data together. The mean number of pages per user in the entire period was 2.5 ; however, the inspection of Fig. $6 \mathrm{~b}$ reveals that the variability of this ratio is very large, and days exist when the mean value has been largely exceeded. This result demonstrates that people browse through the site's pages before leaving.

We maintain that the relation to the occurrences of harmful events depends on new, specific content and the videos that are published during or immediately after harmful events, not only on POLARIS but also on the CNR IRPI social network pages from which people can directly access POLARIS.

\subsection{CNR IRPI Facebook}

Each new content item published on POLARIS was shared via Facebook and Twitter, the two most popular social net- works in Italy. We use Facebook and Twitter CNR IRPI accounts to disseminate simple and immediate messages addressing the geohydrological hazards. In particular, the objective is to increase the public awareness of the frequency and proximity of the geohydrological events and to disseminate media showing hazardous behaviours that pose serious, fatal risks to people.

Analysing the number of referrals from the social networks, corresponding to $14 \%$ of the total, we found that the majority $(80 \%)$ originates from Facebook. The simpler modality of sharing content offered by Facebook with respect to a website makes the publication of links and videos easier. Social media is very widely used when a severe weather condition is occurring. Therefore, it is relevant to compare the number of people who have viewed the content of the CNR IRPI Facebook page with the occurrence of extreme rainfall conditions and or severe warning declarations of the Italian National Department of Civil Protection. For the purpose, we used Facebook statistics because it is the social network from which the majority of the access to POLARIS was registered. 


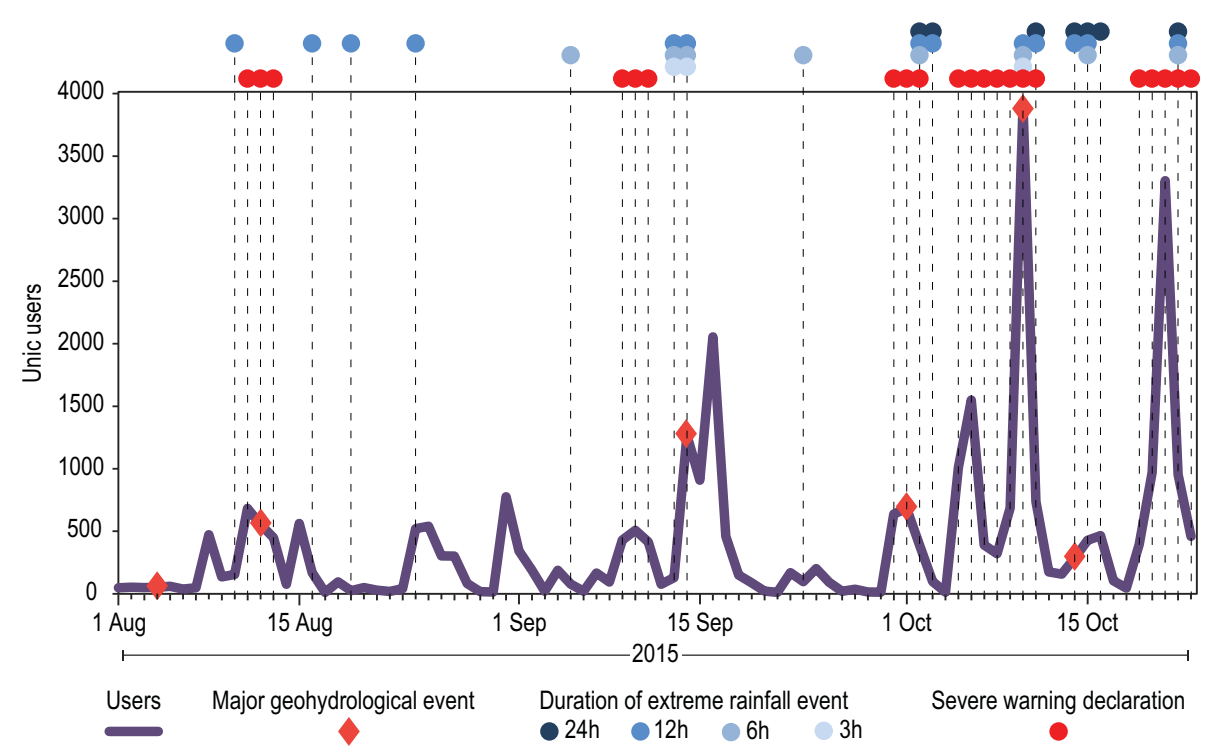

Figure 7. Number of unique Facebook page users. Days with extreme rainfall conditions are marked by blue dots, days with the major geohydrological events are marked by orange diamonds and days with severe warning declarations are marked by red dots.

To define the extreme rainfall conditions that occurred in Italy, we exploited an analysis based on hourly rainfall measurements. The analysis was performed in the 84-day period between 1 August and 23 October 2015. We exploited subhourly rainfall measurements by more than 2000 rain gauges distributed over the entire Italian territory. According to the method described by Rossi et al. (2015), the empirical cumulative distribution function (ECDF) of the cumulative rainfalls has been modelled for each rain gauge. The function allows the calculation of the non-exceedance probability for any given cumulative rainfall and for a set of predefined durations $(3,6,12,24 \mathrm{~h})$, which estimates the non-exceedance probability of the cumulated rainfalls for each rain gauge. To obtain a continuous representation for the entire Italian territory, the rain gauge data have been interpolated using an inverse distance-weighted (IDW) algorithm. This process resulted in a set of four (one for each duration) raster maps that show the non-exceedance probability of the cumulative rainfalls. The maps have been analysed to identify the days when at least $10 \%$ of the Italian territory was interested, using a non-exceedance probability of $80 \%$. This probability value corresponds to cumulative rainfall events that can be defined as extreme events and that could have triggered geohydrological events.

The results of the analyses showed that, in the considered period, the extreme conditions occurred 6 times for a duration of $3 \mathrm{~h}, 12$ times for a duration of $6 \mathrm{~h}, 15$ times for a duration of $12 \mathrm{~h}$ and 7 times for a duration of $24 \mathrm{~h}$. We plotted these extreme conditions in the daily distribution of Facebook users shown in Fig. 7. We observed that extreme conditions, represented by blue dots on the basis of their duration, occurred on 16 days (19\% of the days in the inves- tigated period), grouped into 11 meteorological events that lasted one or more days. On the graph, we plotted the days for which it is known that severe warnings of the Italian National Department of Civil Protection were enacted with a red icon, while the days when severe geohydrological events occurred are shown in orange in Fig. 7. Analysing the four highest peaks, the first (16 September 2060 peak value) corresponds to the publication of videos and images regarding the Piacentino (Emilia-Romagna region) flood event of 1314 September 2015, which caused three deaths and serious damage. The second event on 6 October corresponds to the publication of a revisit of the Vajont disaster (the most disastrous landslide event that has occurred in Italy) in POLARIS at a date near the event's anniversary; this was immediately shared with Facebook. A few days later, on 10 October, the publication of a video showing cars dragged by the water flow caused by heavy rainfall in the Tyrrhenian Messina area (Sicily region) caused a 3916 peak value; finally, the peak of 21 October related to the publication of content that triggered a strong debate. Although the 3-month investigation period is very short, we can observe that, apart from the first half of August, there is suitable correspondence with the rainfall extreme conditions and the peak values of Facebook access. In addition, the peak values correspond to the content that was published and shared.

\section{Discussion}

In POLARIS we define risk communication as a two-way exchange of related information and knowledge on natural hazards and associated risk for the population. The Blog section of the website mainly encourages bottom-up feedback 
through visitor's comments. The link to Facebook stimulates more feedback from citizens who upload pictures and make posts on Facebook. This means that participation, for which the central elements are influence, interaction and information exchange (Bostenaru Dan, 2004), is mainly facilitated by the link with Facebook. However, the website Blog section remains less active than we expected, for at least two reasons: first, the perception of geohydrological hazards in Italy is still very weak, people show less interest toward these geohydrological events than to other natural hazards such as seismic risk (Salvati et al., 2014). Second, people do not know how a geohydrological event can hit them. People are interested in actively participating through the blog section, mainly when a particularly disastrous event is occurring, and in such a case by simply uploading videos and pictures rather than asking for explanations or advice. This means that, despite many institutions making efforts to increase the public understanding of geohydrological risk through nationwide awareness campaigns (e.g. I do not risk, http://iononrischio. protezionecivile.it/), people still ignore how a large part of the Italian territory suffers from geohydrological risk. Such an underestimation of the possible risks and the high confidence in the local administrators towards which citizens delegate their personal safety are factors that impede effective risk communication.

It is important to highlight that POLARIS offers knowledge-oriented risk communication which tends to operate continuously and does not release warning messages in the event of a disaster. The communication efforts seek to change people's attitudes to geohydrological hazards that they may have encountered, giving many examples of what had happened before. People will not react to risk warnings if foregoing communication has not motivated and prepared them.

For this purpose, we are going to evolve the Blog section of POLARIS, which is the most relevant for stimulating public participation at any moment. In particular, we plan to integrate other relevant social media, such as Instagram and Pinterest, stimulating the sharing of images and videos and associated tags and comments. To encourage more resilient behaviour during the occurrences of hazardous events, we would stimulate the usage of video through the YouTube and Vimeo channels, which we can comment on for feedback and/or advice. Finally, we are going to create new synergies with the "I do not risk" campaign and website of the Italian Department of Civil Protection, which will increase traffic, information exchange and, as such, strengthen the risk perception of the Italian population.

\section{Concluding remarks}

The analysis we conducted in the 21 months after publication of the POLARIS website allowed for the following considerations. The geographical distribution of people interested in the published topics is widespread throughout Italy, with a few geographical areas in which sessions are highly concentrated. After the home page, the most viewed website section is the Report, followed by the Focus and Events sections. In a period shorter than two years, the number of sessions has generally increased; however, we observed that in 2015 the most significant positive step occurred. The analysis of the time series, performed to identify possible periodical signals in the daily distribution of sessions, did not highlight any relevant information.

Monitoring the access of users to the POLARIS website and the number of page views during its publication period from 16 January 2014 to 15 October 2015, we noticed that the peak values frequently correspond to the occurrence of particularly damaging geohydrological events. However, inspection of the daily statistics available for CNR IRPI Facebook demonstrated that a correspondence exists between the extreme rainfall events and the number of people who have viewed the content of the Facebook page. This finding was expected because the CNR IRPI Facebook page's objective is to capture the attention of the public at large by proposing content that satisfies their curiosity and their immediate interest during extreme events, which increases the number of followers. Because the Facebook page is linked to POLARIS, an increase in Facebook followers can trigger a gradual increase in the number of people interested in more structured and specialised content and data on geohydrological topics such as those published on POLARIS. Similarly, the specific, science-based POLARIS content, which is focused on geohydrological hazard and risk, became a source of information for journalists and media operators. The growth of user access when media operators publicised the website suggested that we enhance our collaboration with scientific journalists by linking traditional (e.g. television) and social media to further expand awareness of the website and to better explain to users how to exploit the website information.

The POLARIS initiative demonstrates how the scientific community can implement different communication strategies to enhance an effective process that helps different audiences to understand (i) how risks associated with geohydrological hazards are estimated and (ii) how risks can be reduced by increasing the knowledge of the population.

Acknowledgements. We thank Salvatore Buda and Vito Lo Re for the website design and info-graphic development and Mauro Rossi for making the non-exceedance probability cumulative rainfall maps' rainfall data series available. The study was partially financed by the Italian National Department of Civil Protection (DPC). Cinzia Bianchi was supported by a grant from the DPC.

Edited by: S. Illingworth

Reviewed by: G. Bambara and M. Bostenaru-Dan 


\section{References}

Beck, U.: Risk Society: Towards a New Modernity, Published in association with Theory, Culture \& Society, SAGE Publication, 260 pp., 1992.

Bier, V. M.: On the state of the art: risk communication to the public, Reliab. Eng. Syst. Safety, 71, 139-150, doi:10.1016/S09518320(00)00090-9, 2001.

Bostenaru Dan, M. D.: Review of retrofit strategies decision system in historic perspective, Nat. Hazards Earth Syst. Sci., 4, 449-462, doi:10.5194/nhess-4-449-2004, 2004.

Faulkner, H. and Ball D.: Environmental hazards and risk communication, Environmental Hazards, 7, 71-78, doi:10.1016/j.envhaz.2007.08.002, 2007.

Fernández-Bilbao, A. and Twigger-Ross, C.: Improving Response, Recovery and Resilience, Improving Institutional and Social Responses to Flooding, Science Report SC060019, Work Package 2, Environment Agency, Bristol, 134 pp., 2009.

Frewer, L.: The public and effective risk communication, Toxicol. Lett., 149, 391-397, doi:10.1016/j.toxlet.2003.12.049, 2004.

Jonkman S. N. and Dawson R.: Issues and Challenges in Flood Risk Management - Editorial for the Special Issue on Flood Risk Management, Water, 4, 785-792, doi:10.3390/w4040785, 2012.

Guzzetti, F. and Tonelli, G.: Information system on hydrological and geomorphological catastrophes in Italy (SICI): a tool for managing landslide and flood hazards, Nat. Hazards Earth Syst. Sci., 4, 213-232, doi:10.5194/nhess-4-213-2004, 2004.

Guzzetti, F., Cardinali, M., and Reichenbach, P.: The AVI Project: A bibliographical and archive inventory of landslides and floods in Italy, Environ. Manage., 18, 623-633, doi:10.1007/BF02400865, 1994.

Guzzetti, F., Stark, C. P., and Salvati, P.: Evaluation of flood and landslide risk to the population of Italy, Environ. Manage., 36, 15-36, doi:10.1007/s00267-003-0257-1, 2005.

Höppner, C., Bründl, M., and Buchecker, M.: Risk communication and natural hazards. WP5 Report, Swiss Federal Research Institute WSL, available at: http://caphaz-net.org/outcomes-results/ CapHaz-Net_WP5_Risk-Communication.pdf (last access: 20 June 2016), 2010.

Kashefi, E. and Walker, G.: How the Public and Professional Partners Make Sense of Information About Risk and Uncertainty - Literature Review, Science Project SC070060, Environment Agency, Bristol, 2009.

Leiss, W.: Three phases in the evolution of risk communication practice, Ann. Am. Acad. Polit. Soc. Sci., 545, 85-94, doi:10.1177/0002716296545001009, 1996.

Nenciu Posner, C. and Armas, I.: Conceptual approaches concerning risk, vulnerability and adaptation, Riscurişi Catastrofe, 15, 7-24, 2014.

McEntire, D.: Disaster Response and Recovery: Strategies and Tactics for Resilience, Wiley, Hoboken, 294 pp., 2006.
Miles, B. and Morse S.: The role of news media in natural disaster risk and recovery, Ecol. Econ., 63, 365-373, doi:10.1016/j.ecolecon.2006.08.007, 2007.

O'Neill, P.: Developing a risk communication model to encourage community safety from natural hazard, available at: http: //www.ses.nsw.gov.au/content/documents/pdf/research-papers/ 42904/Developing_a_risk_communication_model.pdf, 2004.

Petley, D.: Global patterns of loss of life from landslides, Geology, 40, 927-930, doi:10.1130/G33217.1, 2012.

Plapp T. and Werner, U.: Understanding risk perception from natural hazard: Example from Germany, in: Risk21 - Coping with Risks due to Natural Hazards in the 21st Century, edited by: Ammann W., Dannenmann S., Vulliet L., Taylor and Francis, London, 101-108, 2006.

Plattner Th., Plapp T., and Hebel B.: Integrating public risk perception into formal natural hazard risk assessment, Nat. Hazards Earth Syst. Sci., 6, 471-483, doi:10.5194/nhess-6-471-2006, 2006.

Renn, O., White paper on Risk Governance: Towards an integrative approach, International risk governance council, Geneva, 156 pp., 2005.

Rossi, M. Torri, D., and Santi, E.: Bias in topographic thresholds for gully heads, Nat. Hazards, 79, Supplement 1, 51-69, doi:10.1007/s11069-015-1701-2, 2015.

Rowe, G. and Frewer, L. J.: A Typology of Public Engagement Mechanisms. Sci. Technol. Hum. Val., 30, 251-290, doi:10.1177/0162243904271724, 2005.

Salvati, P., Bianchi, C., Rossi, M., and Guzzetti, F.: Societal landslide and flood risk in Italy, Nat. Hazards Earth Syst. Sci., 10, 465-483, doi:10.5194/nhess-10-465-2010, 2010.

Salvati, P., Bianchi, C., Rossi, M., and Guzzetti, F.: Flood Risk in Italy, in: Changes of flood risk in Europe, edited by: Kundzewicz, Z., IAHS Special Publication 10, IAHS Press, UK, 277-292, 2012.

Salvati P., Marchesini I., Balducci V., Bianchi C., and Guzzetti F.: A New Digital Catalogue of Harmful Landslides and Floods in Italy, in: Landslide Science and Practice, Proceedings of the Second World Landslide Forum, Rome, 19-25 September 2011, edited by: Margottini, C., Canuti, P., and Sassa, K., Vol. 3: Spatial Analysis and Modelling, 409-414, 2013.

Salvati, P., Bianchi, C., Fiorucci, F., Giostrella, P., Marchesini, I., and Guzzetti, F.: Perception of Flood and Landslide Risk in Italy: a Preliminary Analysis, Nat. Hazards Earth Syst. Sci., 14, 25892603, doi:10.5194/nhess-14-2589-2014, 2014.

Scolobig, A., Prior, T., Schroter, D., Jorin, J., and Patt, A.: Towards people-cantered approaches for effective disaster risk management: Balancing rhetoric with reality, Int. J. Disaster Risk Reduct., 12, 202-212, doi:10.1016/j.ijdrr.2015.01.006, 2015.

Steelman, T. A. and McCaffrey, S.: Best practices in risk and crisis communication: Implications for natural hazards management, Nat. Hazards, 65, 683-705, doi:10.1007/s11069-0120386-z, 2013. 